\title{
The effects of clonidine and yohimbine on novelty-induced hypoalgesia
}

\author{
JOSEPH ROCHFORD \\ Concordia University, Montreal, Quebec, Canada
}

\begin{abstract}
Exposure to novel stimuli has been shown to provoke hypoalgesia. The present experiment was conducted to determine whether this hypoalgesia can be influenced by preadministration of the alpha-2 noradrenergic receptor agonist clonidine and the alpha-2 receptor antagonist yohimbine. One group of male Wistar rats $(275-300 \mathrm{~g}$ ) was exposed to a nonfunctional hot-plate apparatus for $90 \mathrm{sec}$, once a day for 8 days. A second group was not exposed to the apparatus. Both groups were subsequently assessed for pain sensitivity on the functional $\left(48.5^{\circ} \mathrm{C}\right)$ hot plate. Animals not previously exposed to the hot plate displayed significantly longer paw-lick latencies than did exposed animals. Preadministration of clonidine $(2 \mu \mathrm{g} / \mathrm{kg}$ i.p.) was found to reverse this hypoalgesia, whereas pretreatment with yohimbine $(2 \mathrm{mg} / \mathrm{kg}$ i.p.) enhanced the effect. These results suggest the importance of noradrenergic substrates in the mediation of novelty-induced hypoalgesia.
\end{abstract}

It is now well demonstrated that exposure to novel environmental stimuli, such as the apparatus to which animals are exposed when tested for pain sensitivity, alters pain threshold (Abbott, Franklin, \& Connell, 1986; Bardo \& Hughes, 1979; Gamble \& Milne, 1989; Rochford \& Stewart, 1987; Sherman, 1979). Specifically, animals exposed to a stimulus for the first time are hypoalgesic relative to animals previously familiarized with the stimulus. Novelty-induced hypoalgesia is resistant to pretreatment with the opiate receptor antagonist naloxone, which suggests that the effect may be mediated by nonopioid antinociceptive substrates (Rochford \& Stewart, 1987).

Research investigating the neurochemical substrates that mediate novelty-induced hypoalgesia has been relatively sparse. To date, research has focused exclusively on serotonergic substrates in the mediation of the effect $(\mathrm{Ab}-$ bott et al., 1986; Gamble \& Milne, 1989). The present experiment was conducted to determine the possible contribution of noradrenergic mechanisms. Noradrenalin was considered a likely candidate on the basis of studies that demonstrated its involvement in a number of behaviors evoked by novelty (Britton, Ksir, Britton, Young, \& Koob, 1984; Delini-Stula, Mogilnicka, Hunn, \& Dooley, 1984) as well as its importance in the mediation of a variety of nonopioid forms of environmentally induced hypoalgesia (Bodnar, Mann, \& Stone, 1985; Chance \& Schechter, 1979; Coderre \& Rollman, 1984; Minor et al., 1988). Moreover, current evidence suggests that these nonopioid forms of hypoalgesia are more sensitive to alpha-2 noradrenergic receptor ligands than to ligands that

This research was supported by a grant from the Fonds pour la Formation de Chercheurs et L'Aide à la Recherche (Quebec). I thank Patricia Dawes for technical assistance. Correspondence concerning this article should be addressed to Joseph Rochford, who is now at the Douglas Hospital Research Centre, 6875 Boul. LaSalle, Verdun, PQ, Canada H4H 1 R3. are less selective for this receptor subtype (Bodnar, Merrigan, \& Sperber, 1983; Chance, 1986; Kepler \& Bodnar, 1988; Lewis, Terman, Nelson, \& Liebeskind, 1984; Rochford, Dubé, \& Dawes, in press). Consequently, the present experiment assessed the effects of clonidine and yohimbine on novelty-induced hypoalgesia. These ligands are selective agonists and antagonists, respectively, for the alpha-2 receptor (Ruffolo, DeMarinis, Wise, \& Hieble, 1988).

\section{METHOD}

\section{Subjects}

The subjects were 32 experimentally naive, male Wistar rats obtained from Charles River Breeding Farms, St. Constant, Quebec. The rats weighed between 275 and $300 \mathrm{~g}$ upon arrival. They were individually housed and provided with free access to both food and water. The colony room was maintained on a 12:12-h light:dark cycle (lights on 0800-2000 h). All procedures were conducted during the light phase of the cycle.

\section{Apparatus and Drugs}

Pain sensitivity was assessed by the hot-plate test. The hot-plate apparatus consisted of a $20 \times 20 \times 38 \mathrm{~cm}$ clear Plexiglas chamber mounted on a piece of sheet metal. The hot-plate temperature was controlled by immersing the sheet metal in a water bath heated by a Haake E3 immersion/open bath circulator. The apparatus was located in a test room illuminated by two $25-\mathrm{W}$ red light bulbs and maintained at a constant $22^{\circ} \mathrm{C}$ temperature. Clonidine $\mathrm{HCl}$ and yohimbine $\mathrm{HCl}$ were obtained from Research Biochemicals, Inc., Nattick, MA. Clonidine was dissolved in $0.9 \%$ saline, yohimbine in distilled water. The injection volume in each case was $1 \mathrm{ml} / \mathrm{kg}$.

\section{Procedure}

The rats were randomly allocated to one of two exposure conditions ( $n=16$ per condition). The animals in the exposure condition were transported to the test room and $30 \mathrm{~min}$ later were placed in the hot-plate chamber for $90 \mathrm{sec}$. The bath circulator was not functional during these exposures; thus, the floor of the chamber was at room temperature. Exposures took place once per day for 8 consecutive days. The animals in the no-exposure condition re- 
mained in their home cages throughout this phase of the experiment and were handled for approximately 1 min per day in the colony room.

Following completion of the exposure phase of the experiment, the rats within each condition were randomly assigned to two groups $(n=8)$. The test phase of the experiment consisted of 2 days. On each day, all rats received an i.p. injection in the colony room $15 \mathrm{~min}$ prior to being transported to the test room. Thirty minutes after being transported, the rats received a hot-plate $\left(48.5^{\circ} \pm 0.5^{\circ} \mathrm{C}\right)$ test. The latency to lick a hind paw was manually recorded. If no response occurred within $90 \mathrm{sec}$, the test was terminated (to prevent tissue damage) and a paw-lick latency of $90 \mathrm{sec}$ was assigned.

The groups differed with respect to the drug administered in the colony room. One group within each exposure condition was administered $2 \mu \mathrm{g} / \mathrm{kg}$ clonidine; the other received $2 \mathrm{mg} / \mathrm{kg}$ yohimbine. These doses were selected on the basis of previous data from my laboratory that demonstrated that they modulate nonopioid hypoalgesia (Rochford \& Dawes, in press). Half of the animals within each group received the respective drug on Day 1 of the test phase and were administered saline on Day 2 . For the other half of the animals, the sequence was reversed

\section{RESULTS}

Because preliminary analysis of the data failed to reveal a significant main effect for, or interaction including, counterbalancing of the colony-room injection sequence (i.e., drug-saline vs. saline-drug), the data were collapsed over this factor and analyzed with a split-plot exposure condition (exposure vs. no exposure) $\times$ drug (clonidine vs. yohimbine) $\times$ colony-room injection (drug vs. saline) analysis of variance (ANOVA). The results from the test phase are presented in Table 1. The ANOVA revealed a significant exposure $\times$ drug $\times$ colony-room injection interaction $[F(1,29)=11.93, p<.002] . F$ tests for simple main effects (Winer, 1971, pp. 529-532) revealed that when saline was preadministered in the colony room, the animals in both no-exposure groups exhibited significantly longer paw-lick latencies than did those in the exposure groups $[F \mathrm{~s}(1,43) \geq 9.29, p \mathrm{~s}<.005]$, which indicates the hypoalgesic effect of novelty. The latencies observed when nonexposed animals were administered clonidine were significantly shorter than the latencies displayed when these animals were administered saline $[F(1,28)=12.45, p<.005]$. Yohimbine administration augmented latencies in nonexposed animals relative to saline administration $[F(1,28)=20.58, p<.001]$. Clonidine and yohimbine did not significantly alter laten-

Table 1

Mean Paw-Lick Latencies $( \pm 1 S E)$ as a Function of Exposure Condition, Drug, and Colony-Room Injection

\begin{tabular}{llllll}
\hline & \multicolumn{3}{c}{ Colony-Room Injection } \\
\cline { 2 - 3 } \cline { 5 - 6 } Exposure & \multicolumn{2}{c}{ Drug } & & \multicolumn{2}{c}{ Saline } \\
\cline { 2 - 5 } Condition & $M$ & $S E$ & & $S E$ \\
\hline Exposure & & & & \\
$\quad$ Clonidine & 22.61 & 3.23 & 25.69 & 2.54 \\
$\quad$ Yohimbine & 20.94 & 2.16 & 18.61 & 3.63 \\
No exposure & & & & \\
Clonidine & 31.80 & 4.73 & 48.29 & 5.48 \\
Yohimbine & 64.25 & 8.05 & 43.05 & 6.75 \\
\hline
\end{tabular}

cies in animals previously exposed to the hot-plate apparatus $(F \mathrm{~s}<1.0)$.

\section{DISCUSSION}

The results from the present experiment demonstrate that clonidine and yohimbine attenuate and augment noveltyinduced hypoalgesia. These ligands were without effect in animals previousy exposed to the hot-plate apparatus. This pattern of results suggests that noradrenergic substrates mediate novelty-induced hypoalgesia.

Inhibition of serotonergic neurotransmission also attenuates novelty-induced hypoalgesia (Abbott et al., 1986; Gamble \& Milne, 1989). Since clonidine and yohimbine have been shown to influence serotonergic substrates, it is possible that the effects of these ligands were mediated through their serotonergic actions. However, yohimbine's effects on serotonergic substrates are also inhibitory (Dwoskin, Neal, \& Sparber, 1988; Feuerstein, Hertting, \& Jackisch, 1985; Pettibone, Pfleuger, \& Totaro, 1985). Consequently, if yohimbine modulated novelty-induced hypoalgesia through its serotonergic action, this drug should have inhibited, rather than enhanced, noveltyinduced hypoalgesia. Furthermore, clonidine's effects on serotonergic neurotransmission are observed with doses higher than the dose employed here (Geyer \& Lee, 1984; Svensson, Bunney, \& Aghajanian, 1975); doses in the low-microgram range provoke predominantly noradrenergic effects (Karege \& Gaillard, 1990).

The results of the present experiment, therefore, suggest that exposure to novelty induces hypoalgesia, at least in part, by activating noradrenergic substrates. The inhibitory effect of clonidine on novelty-induced hypoalgesia may be attributed to a reduction of noradrenergic neurotransmission provoked by this drug through its actions on inhibitory presynaptic alpha-2 receptors (Anden et al., 1970; Karege \& Gaillard, 1990). The enhancement of the effect provoked by yohimbine suggests an augmentation in noradrenergic neurotransmission mediated through the pharmacological blockade of these same receptors (Dubocovich, 1984; Starke, Borowski, \& Endo, 1975). The lack of effect of clonidine and yohimbine in control animals suggests that repeated exposure to the hot-plate apparatus reduced the ability of this stimulus to activate noradrenergic substrates, thereby rendering the ligands ineffective.

Previous results have demonstrated that novelty-induced hypoalgesia is resistant to naloxone pretreatment (Rochford \& Stewart, 1987). Indeed, naloxone administration retards the reduction of novelty-induced hypoalgesia provoked by repeated exposure. Animals administered naloxone prior to each hot-plate exposure display paw-lick latencies comparable in magnitude to nonexposed animals, and the latencies in these groups are significantly longer than are those in animals exposed to the hot plate without naloxone.

These results suggest that opioid substrates may be responsible for the reduction in noradrenergic transmis- 
sion that results from repeated exposure to the hot-plate apparatus. Two lines of evidence are consistent with this hypothesis. First, electrophysiological and biochemical studies have demonstrated the existence of inhibitory opiate receptors located on noradrenergic neurons (Abercrombie \& Jacobs, 1988; Illes \& Norenberg, 1990; Montel, Starke, \& Weber, 1974; Tanaka et al., 1982). Second, clonidine and yohimbine also attenuate and augment the longer paw-lick latencies observed in animals exposed to the hot-plate apparatus under the influence of naloxone (Rochford \& Dawes, in press). Thus, these ligands exert the same effects in animals exposed to the hot plate for the first time and in animals repeatedly exposed to the hot plate following naloxone administration, but are without effect in animals repeatedly exposed to the hot plate without naloxone. This is consistent with the suggestion that opiate-receptor blockade prevents the diminution of noradrenergic activity provoked by repeated exposure to the hot-plate apparatus.

\section{REFERENCES}

Abbott, F. V., Frankun, K. B. J., \& Connell, B. (1986). The stress of a novel environment reduces formalin pain: Possible role of serotonin. European Journal of Pharmacology, 126, 141-144.

Abercrombie, E. D., JacoBs, B. L. (1988). Systemic naloxone administration potentiates locus coeruleus noradrenergic neuronal activity under stressful but not non-stressful conditions. Brain Research, 441, 362-366.

Anden, N. E., Corrodi, H., Fuxe, K., Hoxfelt, T., Rydin, C., - Svensson, T. (1970). Evidence for a central NA receptor stimulation by clonidine. Life Sciences, 2, 513-523.

BARDO, M. T., Hughes, R. A. (1979). Exposure to a nonfunctional hot plate as a factor in the assessment of morphine-induced analgesia and analgesic tolerance. Pharmacology, Biochemistry \& Behavior, $10,481-485$.

Bodnar, R. J., Mann, P. E., Stone, E. A. (1985). Potentiation of cold water swim analgesia by acute, but not chronic desipramine treatment. Pharmacology, Biochemistry \& Behavior, 23, 749-752.

Bodnar, R. J., Merrigan, K. P., Sperber, E. (1983). Potentiation of cold water swim analgesia and hypothermia by clonidine. Pharmacology, Biochemistry \& Behavior, 19, 447-451.

Britton, D. R., Ksir, C., Birtton, K. T., Young, D., Koob, G. F. (1984). Brain norepinephrine depleting lesions selectively enhance behavioral responsiveness to novelty. Physiology \& Behavior, 33, 473-478.

CHANCE, W. L. (1986). The role of brain and spinal cord norepinephrine in autoanalgesia. Annals of the New York Academy of Sciences, 467, 309-330.

Chance, W. L., \& SChechter, W. D. (1979). Autoanalgesia: Blockade by yohimbine. European Joumal of Pharmacology, 58, 89-90.

Coderre, T. J., Rollman, G. B. (1984). Stress analgesia: Effects of PCPA, yohimbine and naloxone. Pharmacology, Biochemistry \& Behavior, 21, 681-686.

Delini-Stula, A., Mogilnicka, E., Hunn, C., Dooley, D. J. (1984). Novelty-oriented behavior in the rat after selective damage of locus coeruleus projections by DSP-4, a new noradrenergic neurotoxin. Pharmacology, Biochemistry \& Bheavior, 20, 613-618.

DuBocovich, M. L. (1984). Presynaptic alpha-adrenoreceptors in the central nervous system. Annals of the New York Academy of Sciences, 420, 7-25.

Dwoskin, L. P., Neal, B. S., \& Sparber, S. B. (1988). Evidence for antiserotonergic properties of yohimbine. Pharmacology, Biochemistry \& Behavior, 31, 321-326.

Feuerstein, T. J., Hertting, G., \& Jackisch, R. (1985). Endoge- nous noradrenalin as modulator of hippocampal serotonin (5-HT) release: Dual effects of yohimbine, rauwolscine and corynanthine as alpha receptor antagonists and 5-HT-receptor agonists. NaunynSchmiedeberg's Archives of Pharmacology, 329, 216-221.

Gamble G. D., \& MiLne, R. J. (1989). Repeated exposure to sham testing procedures reduces reflex withdrawal and hot-plate latencies: Attenuation of tonic descending inhibition? Neuroscience Letiers, 96 , 312-317

GeYer, M. A., a LEE, E. H. Y. (1984). Effects of clonidine, piperoxan and locus coeruleus lesion on the serotonergic and dopaminergic sys. tems in raphe and arcuate nucleus. Biochemical Pharmacology, 33, 3399-3404.

ILLES, P., NORENBERG, W. (1990). Blockade of alpha-2 adrenoreceptors increases opioid mu-receptor-mediated inhibition of firing rate of rat locus coenuleus neurones. Naunyn-Schmiedeberg's Archives of Pharmacology, 342, 490-496.

Karege, F., Gaillard, J. M. (1990). Metabolism time-course of monoamines in rat brain after low dose of clonidine. Biogenic Amines, 7, 37-48.

KePLeR, K. L., BodNAR, R. J. (1988). Yohimbine potentiates cold water swim analgesia: Re-evaluation of a noradrenergic role. Pharmacology, Biochemistry \& Behavior, 29, 83-88.

Lewis, J. W., Terman, G. W., Nelson, L. R., Liebeskind, J. C. (1984). Opioid and nonopioid stress analgesia. In M. D. Tricklebank \& G. Curzon (Eds.), Stress-induced analgesia (pp. 103-133). New York: Wiley.

Minor, B. G., Danysz, W., Post, C., Jonsson, G., Sunstrom, E., a ARCHER, T. (1988). Noradrenergic and serotonergic involvement in brief shock-induced analgesia in rats. Behavioral Neuroscience, 102, 915-924.

Montel, H., Starke, K., * Weber,, F. (1974). Influence of morphine and naloxone on release of noradrenaline from rat brain cortex slices. Naunyn-Schmiedeberg's Archives of Pharmacology, 283, 357-369.

Pettibone, D. J., Pfleuger, A. B., \& Totaro, J. A. (1985). Comparison of the effects of recently developed alpha-2 adrenergic antagonists with yohimbine and rauwolscine on monoamine synthesis in the rat. Biochemical Phamacology, 34, 1093-1097.

Rochrosd, J., \& DAwes, P. (in preas). Clonidine and yohimbine modulate the effects of naloxone on novelty-induced hypoalgesia. Psychopharmacology.

Rochpond, J., Duse, B., a Dawes, P. (in press). Spinal cord alphe2 receptors medinte conditioned annigeain. Psychopharmacology.

Rochrold, J., \& STEWART, J. (1987). Activetion and expreavion of endogenous pain control mechanisms in rats given repeated nociceptive tests under the influence of naloxone. Behavioral Newrascience, 101, 87-103.

Ruffolo, R. R., JR., DeMarinis, R. M., Wise, M., \&ieble, J. P. (1988). Structure-activity relationships for alpha-2 adrenergic agonists and antagonists. In L. M. Limbird (Ed.), The alpha-2 adrenergic receptors (pp. 115-186). Clifton, NJ: Humana.

Sherman, J. E. (1979). The effects of conditioning and novelty on the rats' analgesic and pyretic response to morphine. Leaming \& Motivation, 10, 381-418.

Starke, K., Borowski, E., a Endo, T. (1975). Preferential blockade of presynaptic alpha-adrenoreceptors by yohimbine. European Journal of Pharmacology, 34, 385.

Svensson, T. H., Bunney, B. S., * Aghajanian, G. K. (1975). Inhibition of both noradrenergic and serotonergic neurons in brain by the alpha-adrenergic agonist clonidine. Brain Research, 92, 291-306.

Tanaka, M., Kohno, Y., Nakagawa, R., IDa, Y., Imori, K., Hoaki, Y., Tsuda, A., NagAsaki, N. (1982). Naloxone enhances stress-induced increases in noradrenaline tumover in specific brain regions in rats. Life Sciences, 30, 1663-1669.

WINER, B. J. (1971). Statistical principles in experimental design (2nd ed.). New York: McGraw-Hill.

(Manuscript received August 16, 1991; revision accepted for publication January 8, 1992.) 